\title{
COMPARAÇÃO DOS MÉTODOS DE EXTRAÇÃO USANDO ULTRASSOM E MICROONDAS FOCALIZADO FRENTE A AVALIAÇÃO DA ATIVIDADE ANTIOXIDANTE E ANTICOLINESTERÁSICA DE SCHINUS TEREBINTHIFOLIUS RADDI
}

\author{
$\underline{\text { Lissandra C. A. Reis }}$; Alexsandro Branco ${ }^{2}$; Calila Teixeira Santos $^{3}$
}

\begin{abstract}
1. Bolsista PIBIC/CNPq, Graduanda em Farmácia, Universidade Estadual de Feira de Santana, e-mail: reislissa@ yahoo.com.br 2. Prof. Dr./Orientador, Departamento de Saúde, Universidade Estadual de Feira de Santana, e-mail: branco@uefs.br 3. Preceptora, Doutoranda do programa de pós-graduação em Biotecnologia, Universidade Estadual de Feira de Santana, e-mail: cal.tsantos@gmail.com
\end{abstract}

PALAVRAS-CHAVE: Schinus terebinthifolius Raddi; Antioxidante; Acetilcolinesterase

\section{INTRODUÇÃO}

O Brasil é um país mundialmente conhecido pela sua biodiversidade no que se refere ao bioma, entretanto esse ecossistema ainda é pouco estudado principalmente no que se refere ao nosso semiárido. De acordo com Moreira (2011), no Brasil há uma ampla variedade de frutos tropicais, nativos e exóticos que oferece muitas possibilidades de exploração econômica, especialmente para as regiões Norte e Nordeste do Brasil. Dentre esses frutos podemos destacar o gênero Schinus pertencente à família Anacardiaceae que do ponto de vista fitoquímico apresentam frutos com uma grande riqueza de metabólitos secundários tais como: taninos, saponinas, alcaloides, biflavonoides e ácidos triterpênicos os quais possuem importantes atividades biológicas.

Baseado nas técnicas de extração existentes na literatura, nossa proposta de trabalho consistiu em lançar mão de métodos não convencionais para obtenção de extratos hidroetanólicos dos frutos de Schinus terebinthifolius Raddi (Aroeira vermelha), assim como, os métodos de Microondas Focalizado e Ultrassom por serem técnicas economicamente e ambientalmente viáveis. A partir dos extratos obtidos por diferentes metodologias foi possível quantificar os teores de compostos bioativos e comparar qual das técnicas empregadas obtiveram melhores resultados frente a atividade antioxidante e atividade acetilcolinesterasica.

\section{MATERIAL E MÉTODOS OU METODOLOGIA (ou equivalente)}

Os frutos da Schinus terebinthifolius Raddi foram coletados na região Senhor do Bonfim - BA, Brasil, Brasil, logo sendo higienizados e em seguida secos em estufa com circulação de ar $\left(50^{\circ} \mathrm{C}\right)$. Em sequência, foi triturado em moinho, e peneirado para obtenção de uma farinha de granulometria uniforme. Os extratos obtidos por Extração Assistida por Microondas Focalizado (FMAE) e a Extração Assistida por Ultrassom (EAU), variaram diversos parâmetros como: polaridades do solvente extrator (etanol, solução hidroetanólica $25-75 \%$ e água, o tempo de extração variou de (5-30 minutos), temperatura de extração $\left(25-60^{\circ} \mathrm{C}\right)$ e potência máxima de 300 W. Foram realizadas 32 extrações onde se utilizou diferentes parâmetros para cada uma delas, sendo 16 FMAE e 16 EAU.

A eficiência de extração foi avaliada pela porcentagem de extração pela forma que se segue: Porcentagem de extração $(\mathrm{p} / \mathrm{p})=$ massa do extrato/massa do material seco $\mathrm{x} 100$. A determinação do teor de fenólicos totais dos extratos foi efetuada em microplacas de 96 poços, utilizando o reagente Folin-Ciocalteau (Merck), as mensurações das absorbâncias em função da concentração foram feitas em Leitora de Elisa a $765 \mathrm{~nm}$, em triplicata e curva padrão do ácido gálico obtido através da regressão linear. Os resultados foram expressos em $\mathrm{mg}$ de fenólicos totais em equivalente de ácido gálico por grama. Quanto à avaliação da atividade antioxidante os extratos foram submetidos, separadamente, a determinação da capacidade de sequestrar 0 radical 2,2-difenil-1-picril-hidrazil (DPPH), a medida da absorbância foi realizada no comprimento de onda de $518 \mathrm{~nm}$ em Leitora de Elisa. Todas as análises foram feitas em triplicata e os valores de CE50 (Efficient Concentration), definida como concentração de antioxidante requerida para sequestrar $50 \%$ dos radicais DPPH. 
O teor de flavonoides totais foi feito em leitora de Elisa, a absorbância foi registrada a 510nm, o teor de flavonoides totais determinado por interpolação da absorbância das amostras contra uma curva de calibração construída com quercetina, e os resultados expressos em $\mathrm{mg}$ de flavonoides totais em equivalente de quercetina por $100 \mathrm{~g}$. As análises foram realizadas em triplicata, sendo os resultados expressos como média \pm desvio padrão (D.P.). Diferenças foram consideradas significativas quando $\mathrm{p}<0,05$, utilizando $\mathrm{o}$ teste $\mathrm{t}$ de Student. Para a atividade anticolinesterasica, a enzima utilizada foi a acetilcolinesterase (AChE) de Electrophorus electricustipo VI (sigma). Em cada posso das microplacas (96 poços) foi utilizado iodeto de

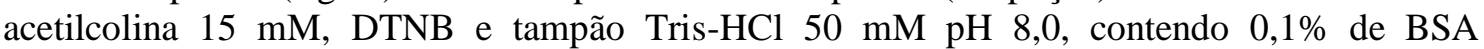
(Albumina do Soro Bovino) e o extrato obtido da Schinus terenbinthifolus Raddi em diferentes concentrações. A absorbância será medida a $405 \mathrm{~nm}$ em leitor de microplaca a cada 13 segundos por 5 vezes. Em seguida foi adicionada a enzima $(0,22 \mathrm{U} / \mathrm{mL})$, e a absorbância foi novamente mensurada.

\section{RESULTADOS E/OU DISCUSSÃO (ou Análise e discussão dos resultados)}

$\mathrm{O}$ rendimento para cada conjunto de condições de extração é apresentado na Tabela 1. Os resultados mostram que o rendimento (\%) de extração varia 11,67- 44,1 no Extrato por microondas focalizado (EAMF) e de 24.6 a 43.7 no Extrato por Ultrassom (EAU).

Tabela 1 - Valores de rendimentos de extração (massa do extrato otimizado/massa da amostrax 100).

\begin{tabular}{llc}
\hline Ensaio & \multicolumn{2}{l}{ Rendimento de extração (\%) } \\
\hline & EAMF & EAU \\
\hline 1 & $32,53 \pm 2.5$ & $30.1 \pm 2.1$ \\
2 & $34,90 \pm 1.8$ & $28.3 \pm 5.8$ \\
3 & $31,64 \pm 10$ & $33.6 \pm 5.0$ \\
4 & $40,52 \pm 2.8$ & $35.4 \pm 2.3$ \\
5 & $38,23 \pm 3.5$ & $39.3 \pm 10.9$ \\
6 & $41,59 \pm 1.4$ & $39.9 \pm 1.6$ \\
7 & $38,72 \pm 1.8$ & $29.1 \pm 10$ \\
8 & $39,93 \pm 4.2$ & $39.8 \pm 1.2$ \\
9 & $32,26 \pm 2.2$ & $33.9 \pm 5.2$ \\
10 & $26,00 \pm 9.8$ & $35.1 \pm 3.9$ \\
11 & $33,30 \pm 4.7$ & $35.8 \pm 0.4$ \\
12 & $39,00 \pm 4.6$ & $43.7 \pm 2.6$ \\
13 & $34,35 \pm 2.2$ & $37.2 \pm 0.8$ \\
14 & $31,00 \pm 4.0$ & $24.6 \pm 1.6$ \\
15 & $38,46 \pm 1.7$ & $36.4 \pm 5.0$ \\
16 & $33,73 \pm 2.0$ & $30.9 \pm 3.4$
\end{tabular}

O conteúdo do Teor de Fenolicos (FT), Teor de flavonoides totais (FLT) e percentagem de sequestro de radicais livres (\%SRL) são apresentados na Tabela 2. O melhor valor de FT foi $5950,0 \pm 1,4 \mathrm{mgEAG} / 100 \mathrm{~g}$ e FLT no valor de $1750,0 \pm 3,2 \mathrm{mg} \mathrm{EQ} / 100 \mathrm{~g}$, representado pelo tempo de extração de 25 minutos, $75 \%$ de etanol e $51{ }^{\circ} \mathrm{C}$ de temperatura, relacionado com EAMF 8. Os ensaios utilizando ultrassom em sua maioria apresentou menores níveis de compostos fenólicos e flavonoides, a melhor condição foi EAU 10 (FT) com 897,3 \pm 1,9 mg EAG/100g e EAU 12 (FLT) com 67,72 $\pm 1,0 \mathrm{mgEQ} / 100 \mathrm{~g}$.

Observa-se que as concentração de fenóis totais na EAMF nos frutos de Schinus terebinthifolius Raddi são próximos de outras frutas como no caso da jabuticaba - polpa congelada 1405,79 \pm 35,97 mg de EAG/100g de amostra e polpa liofilizada 5198,11 $\pm 410,92 \mathrm{mg}$ de EAG/100g de amostra (REZENDE, 2010) e do morangos polpa úmida que apresentou variação de $1586 \mathrm{mg}$ catequina/100g -2892 mg catequina/100g (CORDENUNSI et al. 2002). 
Quando se compara os valores percentuais de sequestro de radicais livres (\% SRL) dos extratos com os padrões, pode-se ver que os extratos por micro-ondas focalizado mostrou forte atividade antioxidante, com a percentagem de sequestro de radicais de DPPH acima de 50\% para uma concentração de $100 \mu \mathrm{g} / \mathrm{ml}$. Já no ultrassom, os extratos apresentaram valores abaixo de $50 \%$, com baixa porcentagem de sequestro de radicais livres.

O melhor valor da \% SRL encontra-se no ensaio EAMF 8 com 87,3 $\pm 0,33 \%$, este ensaio apresentou valor maior que os padrões de ácido ascórbico (AA) e rutina que em média tiveram os valores de 73,7\% $\pm 0,39$ e 66,3\% $\pm 0,34$, respectivamente. Esse mesmo ensaio apresentou valor de EC50 de $\pm 40 \mu \mathrm{g} / \mathrm{ml}$ valor próximo ao encontrado para os padrões que foram: $45,1 \mu \mathrm{g} / \mathrm{ml}$ (AA) e $41,5 \mu \mathrm{g} / \mathrm{ml}$ (rutina). Para os demais ensaios não foi possível determinar o valor de EC50 nas condições usadas neste estudo.

Tabela 2 - Valores de fenólicos totais (FT), flavonoides totais (FLT) e sequestro de radicais livres (\%SRL) dos extratos de etanol de frutos de Schinus terebinthifolius Raddi

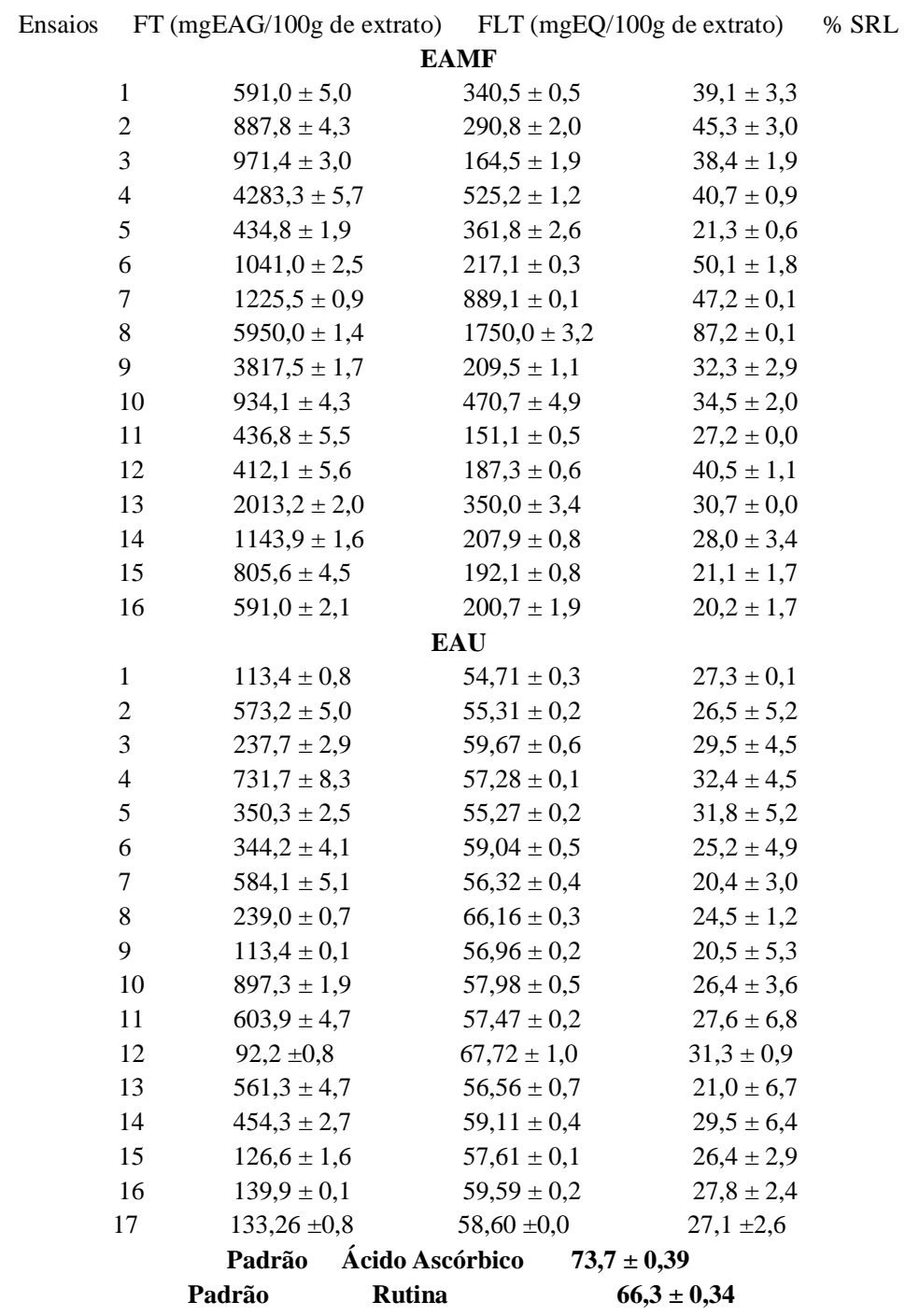

Todos os extratos obtidos pelos dois métodos de extração (micro-ondas focalizada e ultrassom) foram testados na atividade de inibição da acetilcolinesterase, Os dados mostraram que nem todos os extratos foram capazes de influenciar na atividade enzimática da acetilcolinesterase de forma importante na concentração de $1 \mathrm{mg} / \mathrm{ml}$, Os valores de porcentagem de inibição variaram entre 0 a $76 \%$ nos extratos obtidos pelo ultrassom e entre 0 a $54 \%$ nos extratos obtidos pelo micro-ondas focalizado, conforme observa-se na Tabela 3. 
Eldeen et al, (2005) classificam a inibição da atividade acetilcolinesterásica como potente quanto a inibição for maior que 50\%, moderada quando a inibição for de $30-50 \%$ e baixa quando a inibição for menor que $30 \%$. Para este trabalho, os extratos foram considerados ativos quando a inibição da atividade acetilcolinesterásica foi maior que 50\%. Assim sendo os extratos mais ativos foram: EAMF 1 e EAMF 9 e os EAU 12 e EAU 7.

Tabela 3 - Valores da inibição da acetilcolinesterase (\%Inibição ACHE) dos extratos de etanol de frutos de Schinus terebinthifolius Raddi

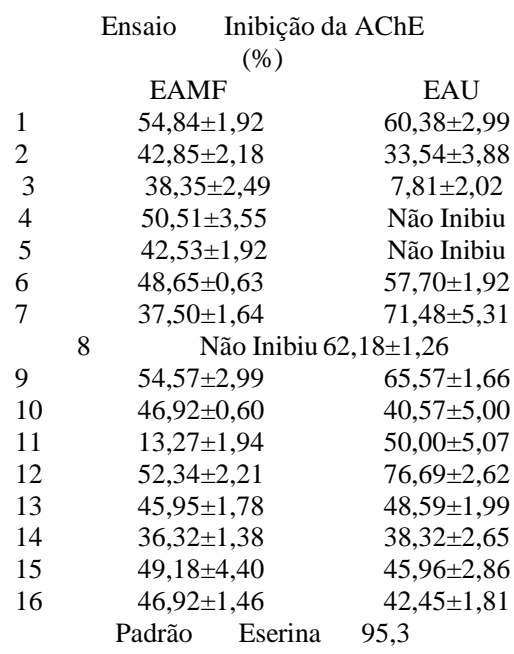

\section{CONSIDERAÇÕES FINAIS (ou Conclusão)}

Após a análise dos resultados podemos inferir que a EAMF é adequada como um procedimento de extração rápido e eficiente. Em relação ao rendimento os métodos utilizados (EAMF e EAU) não apresentaram diferença estatística. A temperatura de $51^{\circ} \mathrm{C}$, a composição do solvente de $75 \%$ etanol e o tempo de extração de 25 min resultaram em uma maior \% de SRL (87,2\%). Os ensaios obtidos pela EAMF apresentaram melhores teores de fenólicos e flavonoides que os ensaios obtidos pela EAU. Os extratos obtidos por ultrassom assistido apresentaram inibição potente da acetilcolinesterase (76,69\%). Os frutos de Schinus terebinthifolius Raddi podem ser considerados como uma fonte potencial de antioxidantes, com alta inibição da acetilcolinesterase, podendo serem utilizados em diversos campos, como nutracêuticos, cosméticos e indústria alimentar.

\section{REFERÊNCIAS}

CORDENUNSI, B. R. et al. Influence of cultivar on quality parameters and chemical composition of strawberry fruits grown in Brazil. Journal of Agricultural and Food Chemistry, v. 50(9), p. 2581-2586, 2002.

ELDEEN, S. M. I.; ELGORASHI, E. E.; STADEN, J. Antibacterial, anti-inflammatory, anticholinesterase and mutagenic effects of extracts obtained from some trees used in South African traditional medicine. Journal of Ethnopharmacology, v. 102, p. 457-464, 2005.

MOREIRA, A. C. C. G. Caracterização de frutos de genótipo de cajá- umbuzeiras: teor de fitoquímicos bioativos e potencial antioxidante. Dissertação (Mestrado). Universidade Federal Rural de Pernambuco, 2011.

REZENDE, L.C. Avaliação da atividade antioxidante e composição química de seis frutas tropicais consumidas na Bahia. Salvador - BA, Universidade Federal da Bahia, 2010, 118p. Tese de Doutorado em Química. Universidade Federal da Bahia (UFBA). 